\title{
Langerhans cells in hypospadias: an analysis of Langerin (CD207) and HLA-DR on epidermal sheets and full thickness skin sections
}

\author{
Bernhard Haid ${ }^{1,2^{*}}$ (D), Daniela Reider ${ }^{3}$, Felix Nägele ${ }^{4}$, Anne-Françoise Spinoit ${ }^{5}$, Elisabeth Pechriggl ${ }^{6}$,
}

Nikolaus Romani ${ }^{3}$, Helga Fritsch ${ }^{4}$ and Josef Oswald ${ }^{1}$

\begin{abstract}
Background: Hypospadias are among the most common genital malformations. Langerhans Cells (LCS) play a pivotal role in HIV and HPV infection. The migration of LC precursors to skin coincides with the embryonic period of hypospadias development and genetic alterations leading to the formation of hypospadias impact the development of ectodermally derived tissues. We hypothesized that this might be associated with a difference in frequency or morphology of epidermal and dermal LCs in hypospadias patients.
\end{abstract}

Methods: A total of 43 patients from two centers were prospectively included into this study after parental consent and ethics approval. Epidermal and dermal sheets were prepared from skin samples of 26 patients with hypospadias, 13 patients without penile malformations and 4 patients with penile malformations other than hypospadias. Immunofluorescence staining of sheets was performed with anti-HLA-DR-FITC and anti-CD207/ Langerin-A594 antibodies. Skin sections from 11 patients without penile malformation and 11 patients with hypospadias were stained for Langerin. Frequencies as well as morphology and distribution of epidermal and dermal LCs on sheets and sections were microscopically evaluated. Cell counts were compared by unpaired t-tests.

Results: There was no difference in frequency of epidermal LCs, Neither on sheets $\left(873 \pm 61 \mathrm{vs.} 940 \pm 84 \mathrm{LCs} / \mathrm{mm}^{2}\right.$, $p=0.522)$ nor on sections ( $32 \pm 3$ vs. $\left.30 \pm 2 \mathrm{LCs} / \mathrm{mm}^{2}, p=0.697\right)$. Likewise, the frequency of dermal LCs $(5,9 \pm 0,9 \mathrm{vs}$. $7.5 \pm 1.3 \mathrm{LCs} / \mathrm{mm}^{2}, p=0.329$ ) was comparable between patients with hypospadias and without penile malformation. No differences became apparent in subgroup analyses, comparing distal to proximal hypospadias $(p=0.949)$, younger and older boys $(p=0.818)$ or considering topical dihydrotestosterone treatment prior to surgery $(p=0.08)$. The morphology of the LCs was not different comparing hypospadias patients with boys without penile malformations.

Conclusions: LCS are present in similar frequencies and with a comparable morphology and distribution in patients with hypospadias as compared to children without penile malformations. This suggests that patients with hypospadias are not different from patients with normal penile development considering this particular compartment of their skin immunity.

Keywords: Langerhans cells, Hypospadias, Foreskin, HPV, HIV

\footnotetext{
*Correspondence: bernhard.haid@ordensklinikum.at

'Department of Pediatric Urology, Hospital of the Sisters of Charity,

Ordensklinikum Linz, Seilerstätte 4, 4020 Linz, Austria

${ }^{2}$ Department of Urology, Ludwig Maximilians University, Marchioninistraße

15, 81367 Munich, Germany

Full list of author information is available at the end of the article
}

(c) The Author(s). 2019 Open Access This article is distributed under the terms of the Creative Commons Attribution 4.0 International License (http://creativecommons.org/licenses/by/4.0/), which permits unrestricted use, distribution, and reproduction in any medium, provided you give appropriate credit to the original author(s) and the source, provide a link to the Creative Commons license, and indicate if changes were made. The Creative Commons Public Domain Dedication waiver (http://creativecommons.org/publicdomain/zero/1.0/) applies to the data made available in this article, unless otherwise stated. 


\section{Background}

Hypospadias affects 1 in 125-300 male births, representing the second most common genital malformation after undescended testes [1]. The malformation of the penis present in hypospadias, however, does not only involve the urethral opening being situated abnormally at the ventral side of the penis. All tissues including skin, notably on the ventral aspect of the penis, seem underdeveloped and altered in appearance. The events related to the formation of hypospadias happen in very early phases of the genital tubercle outgrow starting in gestational week 8; differentiation of the urethral epithelium is determined by mesenchymal signaling [2]. Thereby, not only the organogenesis of the urethra is defined but also prepuce morphogenesis and surface epithelia of ectodermal origin are influenced $[3,4]$.
Except concerning hormonal receptors, the repercussions of these early fetal events on other penile tissues have not yet been adequately investigated $[3,5]$.

Langerhans cells (LCs), the dendritic cells of epithelia, are dispersed in the epidermis as a dense network of immunologic gatekeepers, internalizing possible pathogenic antigens and presenting them to T-cells in draining lymph nodes, thereby initiating and regulating the specific immune response [6]. They are critically involved in human immunodeficiency virus (HIV) and human papillomavirus (HPV) infection [7, 8]. The typical hallmark of human LCs, as opposed to other dendritic cells, is the expression of Langerin (CD207), a C-type lectin serving as pathogen receptor and comprising the archetypical Birbeck granules [9]. LCs develop and seed the epithelial tissues already during embryogenesis, notably in the very

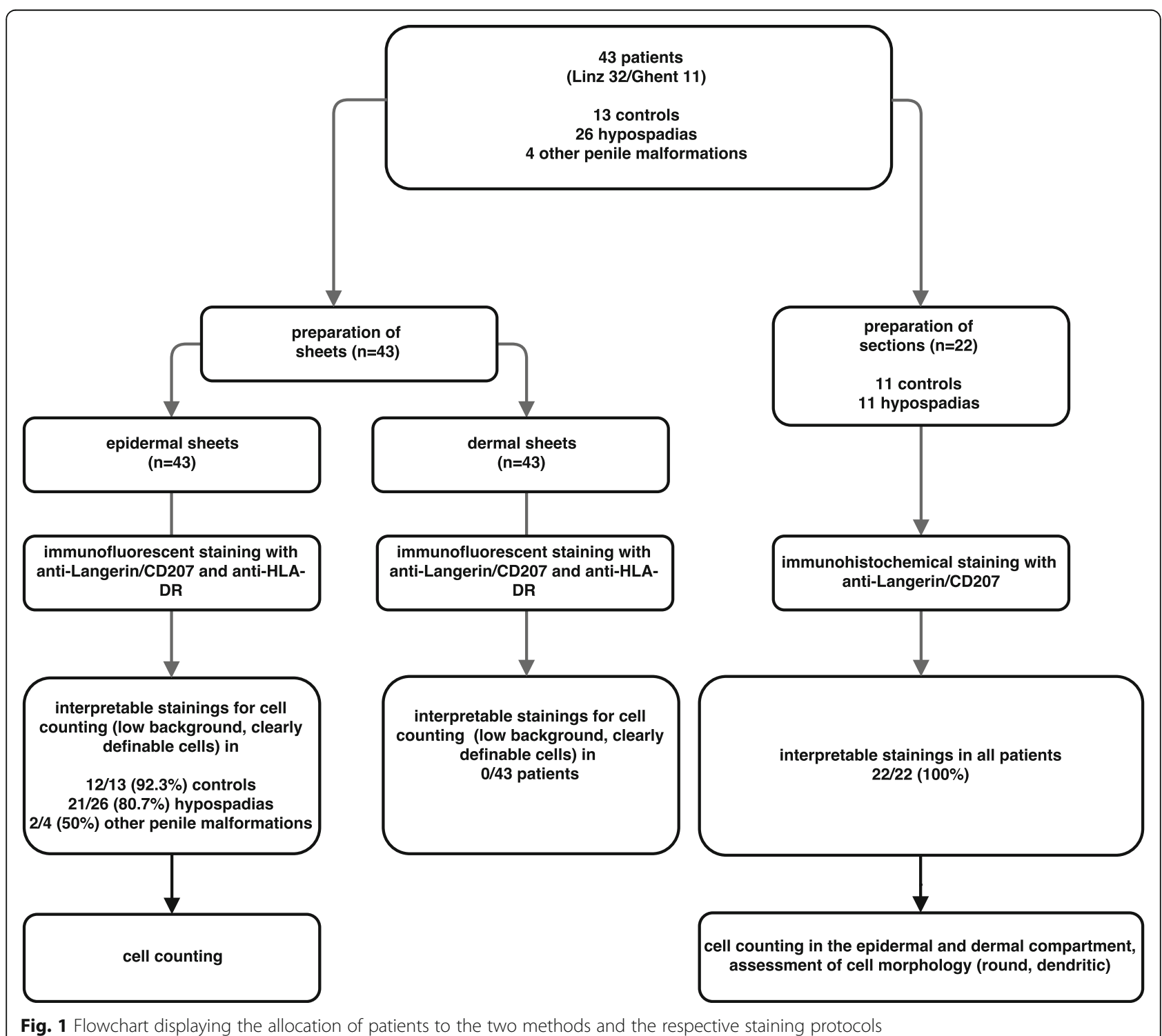

Fig. 1 Flowchart displaying the allocation of patients to the two methods and the respective staining protocols 
Table 1 Patients characteristics

\begin{tabular}{|c|c|c|c|c|}
\hline & $\begin{array}{l}\text { all patients } \\
(n=43)\end{array}$ & $\begin{array}{l}\operatorname{Linz} \\
(n=32)\end{array}$ & $\begin{array}{l}\text { Gent } \\
(n=11)\end{array}$ & $p$ \\
\hline age at surgery mean/median [months] & $49 / 15$ & $36 / 15$ & $26 / 14$ & $0.4^{\mathrm{a}}$ \\
\hline no penile malformation (\%) & $13(30.2 \%)$ & $12(37.5 \%)$ & $1(9.1 \%)$ & \\
\hline hypospadias & $26(60.4 \%)$ & $19(59.4 \%)$ & $7(63.6 \%)$ & \\
\hline distal hypospadias (\% of all hypospadias) & $16(61.5 \%)$ & $11(57.9 \%)$ & $5(71.4 \%)$ & \\
\hline proximal hypospadias (\% of all hypospadias) & $10(38.5 \%)$ & $8(42.1)$ & $2(28.6 \%)$ & \\
\hline thereof with preoperative androgen treatment (local $\mathrm{DHT}^{\mathrm{b}}$ for 6 weeks until 4 weeks before surgery) & $7(70 \%)$ & 7 (87.5\%) & 0 & \\
\hline other penile malformations & $4(9.3 \%)$ & $1(3.1 \%)$ & $3(27.2 \%)$ & \\
\hline buried penis & $2(50 \%)$ & 0 & $2(66.6 \%)$ & \\
\hline epispadias & $2(50 \%)$ & $1(100 \%)$ & $1(33.3 \%)$ & \\
\hline
\end{tabular}

${ }^{a}$ students t-test ${ }^{\mathrm{b}}$ Dihydrotestosterone, applied twice daily

same period when later hypospadias are determined [10]. Differences in function of these specialized immune cells could implicate altered susceptibility to HIV or HPV.

Despite these important implications in the skin immune system, the presence or morphology of Langerhans Cells have never been investigated in patients with hypospadias up to now as to our knowledge.

We hypothesized that due to developmental differences in epithelial embryogenesis, the frequency or morphology and consequently also the function of epidermal and dermal LCs in patients with hypospadias might be altered in comparison to patients without a penile malformation.

\section{Methods}

The study protocol has been approved by the ethics committee of the Hospital of the Sisters of Charity (EK22/14). After informed consent of all parents a total of 43 patients (Linz/Ghent 32/11) were prospectively included.

During surgery, small pieces $\left(7-10 \mathrm{~mm}^{2}\right)$ of whole preputial skin from lateral parts of the prepuce were obtained. Any sign of potential inflammation, for instance balanoposthitis or a clinical suspicion of Lichen Sclerosus as well as a history of balanoposthitis resulted in non-inclusion of the patient. In course of analyzing the samples, all section stainings were checked for histological signs of inflammation (dermal leucocyte infiltration) to subsequently exclude them in order to preclude a potential interference with our results. The preparation steps for the two different methods applied are detailed below. The allocation of specimens to the different methods is displayed in Fig. 1.

Patients' characteristics are presented in Table 1.

In patients with proximal hypospadias and a glans diameter of less than $14 \mathrm{~mm}$, topical dihydrotestosterone $2.5 \%$ gel (Andractim ${ }^{\circ}$ ) was applied over a period of 6 weeks until 4 weeks prior to surgery twice daily.

\section{Sheets}

Immediately after harvesting, skin was freed from subepithelial fatty tissue and conserved in a sterile PBS/1\%BSA (phosphate buffered saline / $1 \%$ bovine serum albumine) solution. At the latest $2 \mathrm{~h}$ thereafter, the skin was floated dermal side down - on $0.5 \mathrm{M}$ ammoniumthiocyanate

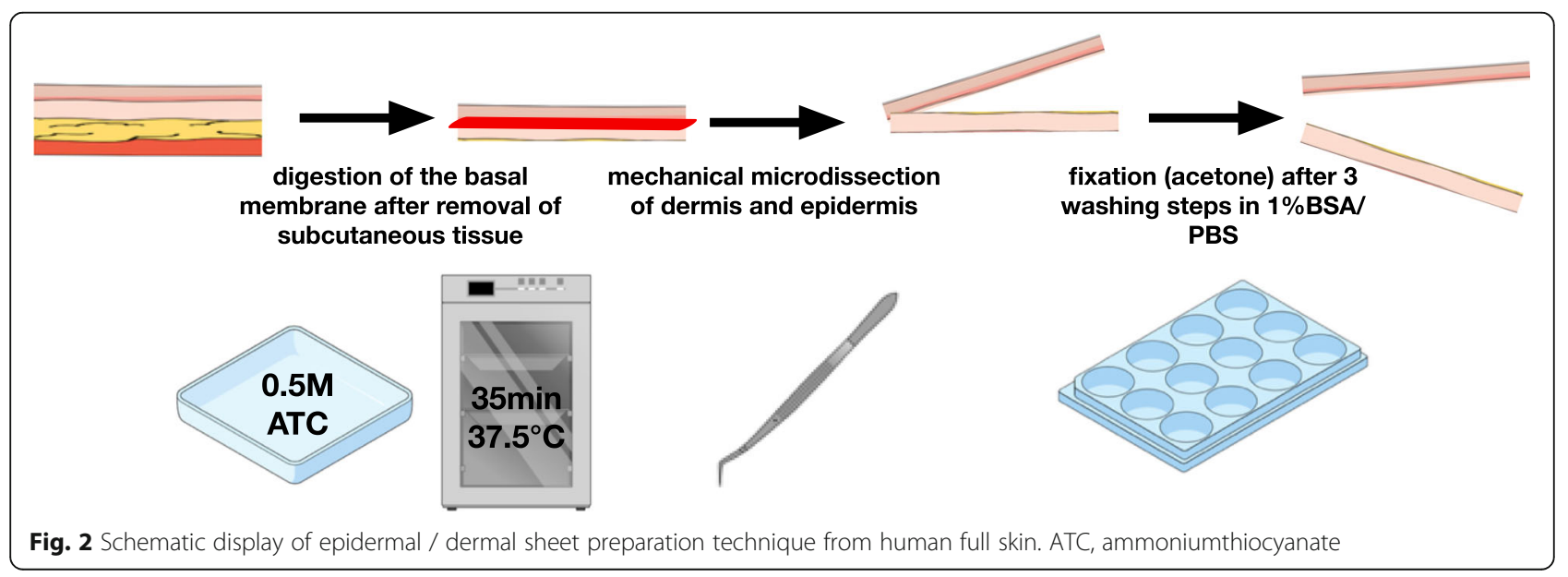


solution for $35 \mathrm{~min}$ at $37^{\circ} \mathrm{C}$. The epidermis was then peeled off the dermis using microsurgical instruments. After fixation (synthesis grade acetone, $20 \mathrm{~min}$ at room temperature) and three washing steps using PBS/1\%BSA, the dermal and epidermal sheets were cut into small pieces $\left(4-5 \mathrm{~mm}^{2}\right)$, frozen in a drop of PBS $/ 1 \% \mathrm{BSA}$ and stored at $-20^{\circ} \mathrm{C}$ [11]. A detailed protocol of sheet preparation is provided in Fig. 2.

After thawing, epidermal as well as dermal sheets were incubated with an unconjugated primary antibody (anti-human CD207/Langerin; clone MB22-9F5, mouse IgG1, Miltenyi
Biotec, Bergisch Gladbach, Germany) for $1 \mathrm{~h}$ at $37^{\circ} \mathrm{C}$, followed by three 10-min washing steps. Subsequently the sheets were incubated with a fluorochrome-coupled secondary antibody (Alexa-Fluor 594-conjugated, isotype-specific goat anti-mouse IgG1, Invitrogen/Thermo-Fisher) for $1 \mathrm{~h}$ at $37^{\circ} \mathrm{C}$, again followed by three 10 -min washing steps. The staining sequence was extended by incubating the sheets with an excess concentration of mouse IgG $(100 \mu \mathrm{g} / \mathrm{ml}))$ to quench residual free binding sites of the preceding antimouse Ig antibodies. Finally, sheets were incubated with

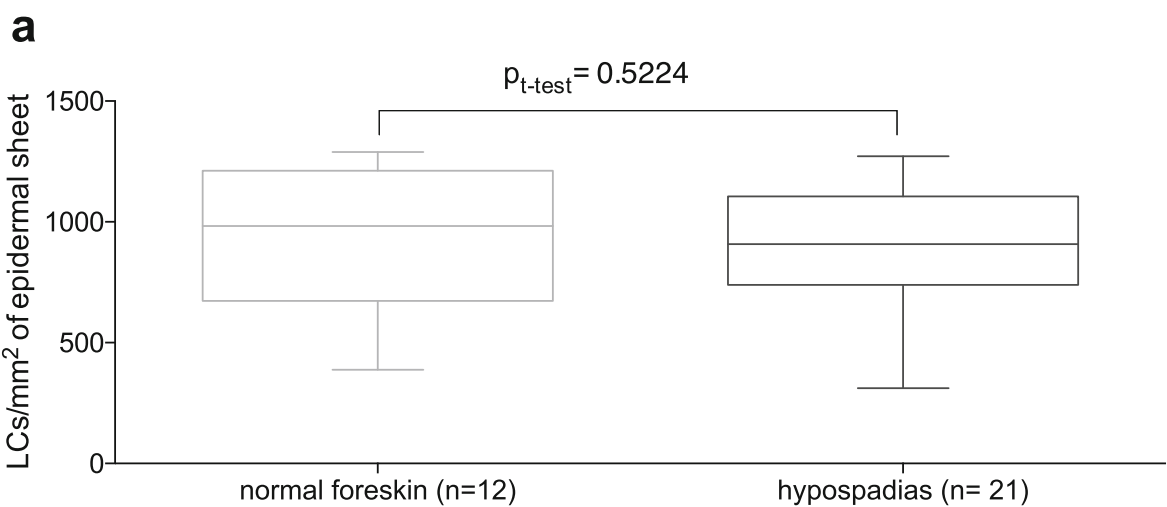

b

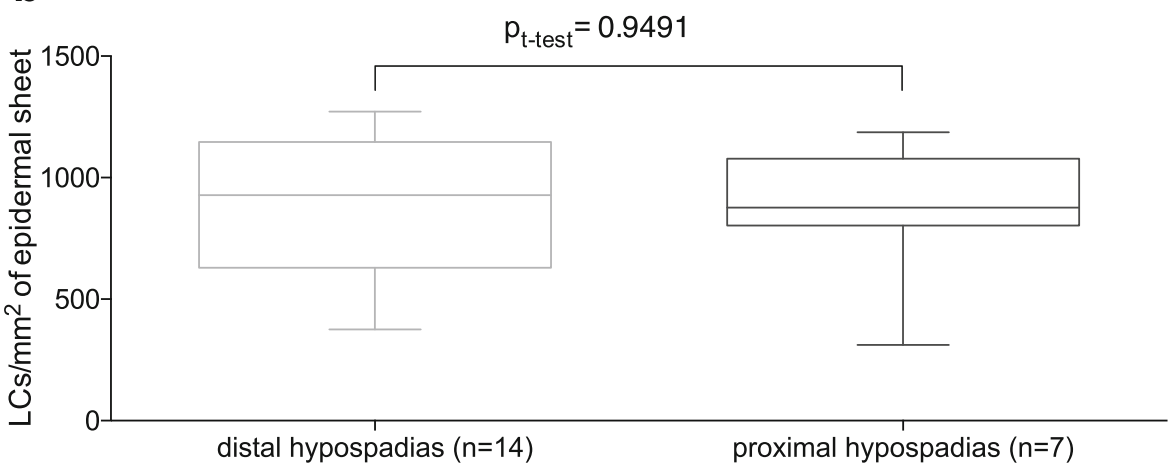

C

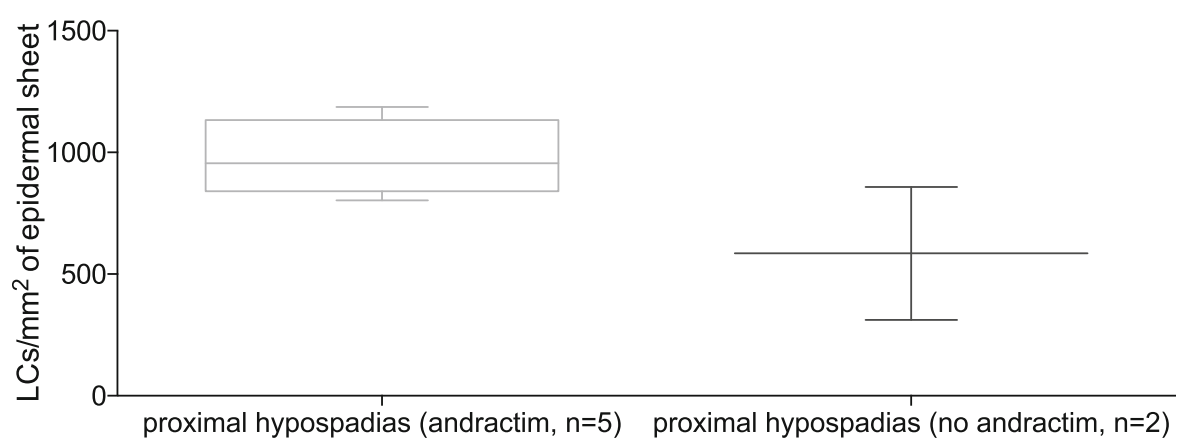

Fig. 3 Box-plots of mean Langerhans cell (LC) counts per $\mathrm{mm}^{2}$ on immunofluorescence stained epidermal sheets comparing a patients without penile malformations to all included patients with hypospadias, $\mathbf{b}$ patients with distal hypospadias to patients with proximal hypospadias, and $\mathbf{c}$ patients with proximal hypospadias who did not receive topical dihydrotestosterone (DHT, andractim) before surgery to those who did receive 6 weeks of DHT until 4 weeks prior to surgery. Error bars represent min-max 
anti-human HLA-DR (clone L243, mouse IgG2a, BioLegend) followed by Alexa-Fluor 488-conjugated, isotype-specific goat anti-mouse IgG2a, Invitrogen/Thermo-Fisher) for 1 hour each at $37^{\circ} \mathrm{C}$. For nuclear staining, dermal sheets were incubated in DAPI dilactate (Invitrogen / Molecular Probes). For each antibody, an isotype control staining was performed to exclude unspecific staining results. Immunolabeled specimens were mounted in Vectashield mounting medium (Vector Laboratories, Burlingame, CA) and analyzed on a conventional fluorescence microscope (Olympus BX60).

Only when an unequivocal epidermal keratinocyte structure ("cobblestone pattern") could be seen in transmission light, stainings were considered valid. Due to the thickness of the dermal part of the sheets, reproducible cell counting in the dermis was not possible using sheets and conventional fluorescence microscopy.

On every epidermal sheet, HLA-DR+ and langerin+ cells cells were counted in 12 high power fields $(40 \times \mathrm{ob}$ jective lens magnification). Density of cells $/ \mathrm{mm}^{2}$ was calculated by means of a calibrated micrometer slide.

\section{Sections}

Immediately after harvesting, full skin of 22 patients (Fig. 1) was fixed in $4 \%$ formaldehyde $(2-4 \mathrm{~h})$ and then immersed in paraffin blocks for conservation and transport. $5 \mu \mathrm{m}$ whole skin sections were prepared on a rotation microtome and mounted on SuperFrost ${ }^{\circ}$ Plus slides. The sections were stained using anti-human CD207/ Langerin (clone 929F3.01 undiluted hybridoma cell supernatant, rat IgG2a, gift of Dr. S. Saeland and Dendritics, Lyon, France) followed by immunohistochemical labeling (Ventana universal secondary antibody, biotinylated IgG anti-goat/mouse/rat; Ventana ultra view DAB-MAP detection kit) using a standardized, automatized staining technique (DAP-MAP IHC discovery research standard protocol, Ventana, Roche ${ }^{\circ}$.

LCs were counted in 4 epidermal and 4 dermal fields that were placed randomly measuring $100 \times 100 \mu \mathrm{m} / \mathrm{sec}-$ tion and patient. Counting and measuring was performed using the Image J Software (National Institute of Health, Bethesda, ML, USA).

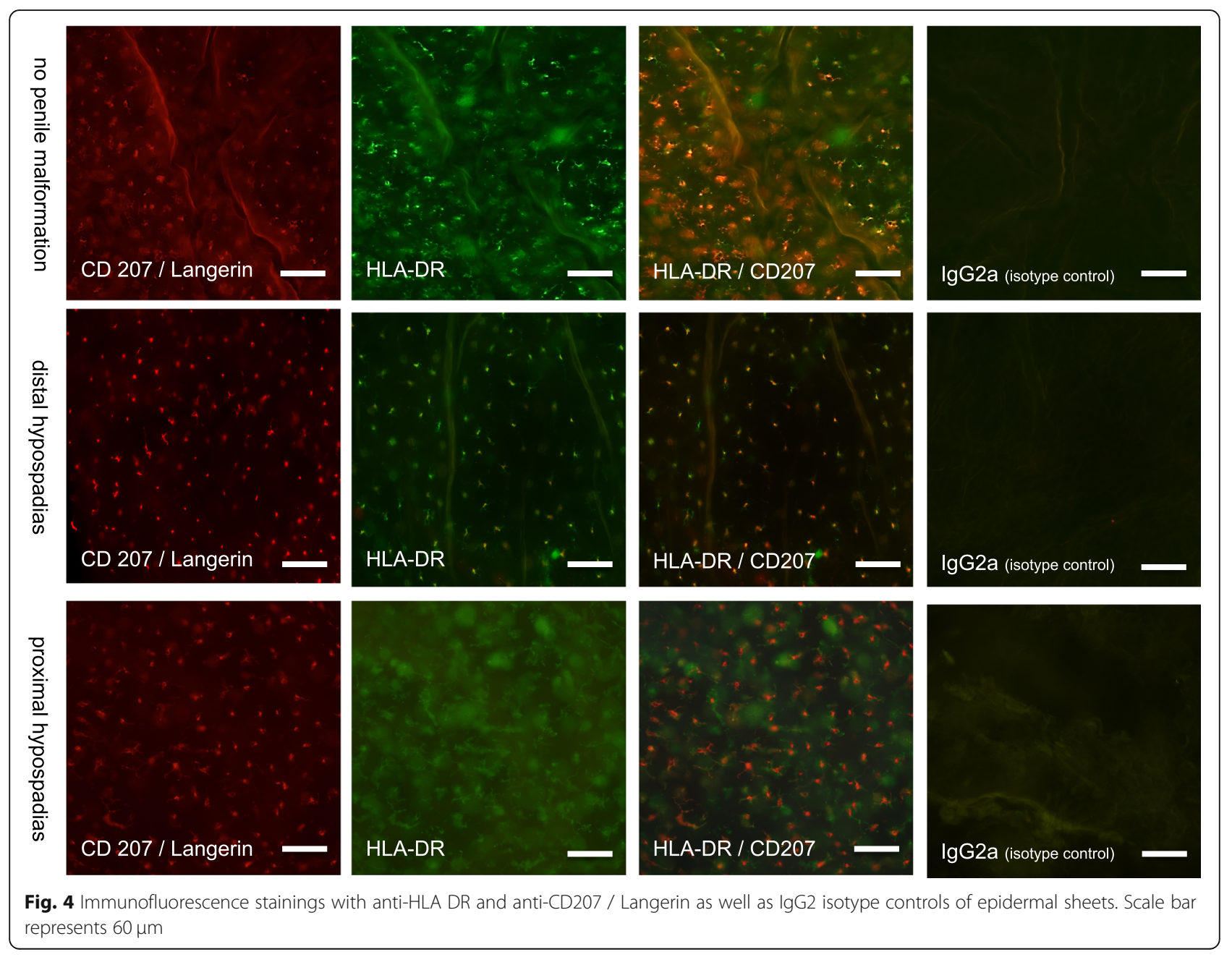


LC morphology was classified into round and dendritic shaped and documented alongside cell counting, specifying the relative proportions of round and dendritic shaped LCs.

\section{Statistics}

Cell counts for epidermal and dermal LCs on sheets as well as on sections were compared by unpaired $t$-tests. The cut-off for the alpha error was defined as $<0.05$, for multiple testing a Bonferroni correction was applied. Data analysis and figure design was performed using Prism 6.0 (Graphpad Software, Inc., San Diego, CA, USA).

\section{Results}

\section{Sheets}

Interpretable staining without signs of inflammation (dermal leucocyte infiltration) could be achieved in samples from 12 patients $(92.3 \%$ of all included patients) without penile malformations, 14 (87.5\%) with distal hypospadias, $7(70 \%)$ with proximal hypospadias, one with buried penis (50\%) and one with epispadias (50\%) translating into a total of $81.4 \%$ of all epidermal sheets prepared being amenable for analysis. HLA-DR/CD207 double positive cells were considered LCs.

The mean frequency of epidermal HLA-DR/CD207 double positive cells per $\mathrm{mm}^{2}$ accounted to $873.4 \pm 61.6$ in patients with hypospadias $(n=21)$ as compared to $940.2 \pm 84.2$ in patients without penile malformation ( $n=12, p=0.522$, $\mathrm{t}$-test). There was no significant difference in LC frequency between distal and proximal hypospadias $(876.2 \pm 78.7, n=14$, distal vs. $867.6 \pm 105.5, n=$ 7 proximal, $p=0.9491)$. Comparing patients with proximal hypospadias who had received topical dihydrotestosterone prior to surgery to those who had not, we found no significant difference in epidermal LC density (585.5 $\pm 273.1, n=2$ vs. $980.4 \pm 68.9, n=5, p=0.0857)$. The morphology of the epidermal LCs was the same in all samples Figs. 3 and 4.

Stainings of the dermal sheets revealed single Langerinpositive cells, however, due to background staining reliable and reproducible cell counting on these sheets was not

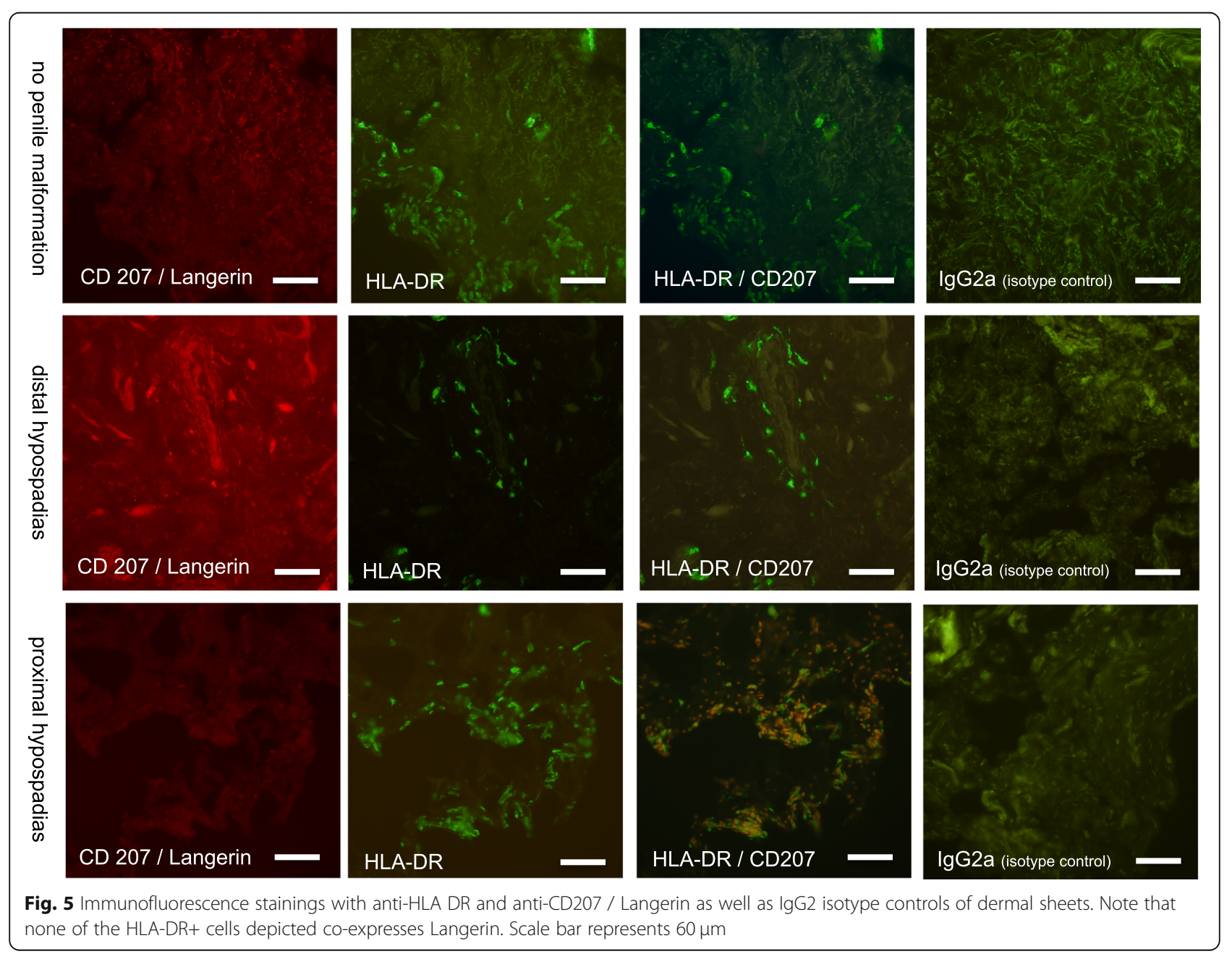


possible with the available microscopic facilities. Figure 5 provides immunofluorescent images showing the dermal sheet staining.

The morphology of the epidermal LCs was comparable in all samples. Most epidermal LCs were dendritically shaped, however, some (10-15\%) were rounded. No conspicuous and consistent differences could be detected in comparison with LCs from healthy foreskin. While most epidermal HLA-DR-positive cells were also Langerin positive, on some sheets we found areas with intermingled HLA-DR single positive cells. Sample images of single Langerhans cells and their morphology, as defined for this project, are shown in Fig. 6.
LC frequency accounted to $930.3 \pm 65.61(n=14)$ in patients < 1 year of age, $1028 \pm 80.26(n=7)$ in patients between 1 and 3 and 907.0 $\pm 75.65,(n=14)$ in patients over 3 years of age $(p=0.818<1$ vs. $>3$ years of age) Fig. 7 .

The patient with buried penis had a mean LC count of $880.3 / \mathrm{mm}^{2}$. In the single interpretable staining of a patient with epispadias we found $1055.79 \mathrm{LCs} / \mathrm{mm}^{2}$.

\section{Sections}

On all stained sections $(n=22,11$ hypospadias, 11 patients without penile malformation), clearly evaluable staining results were achieved. Dermal as well as epidermal LC

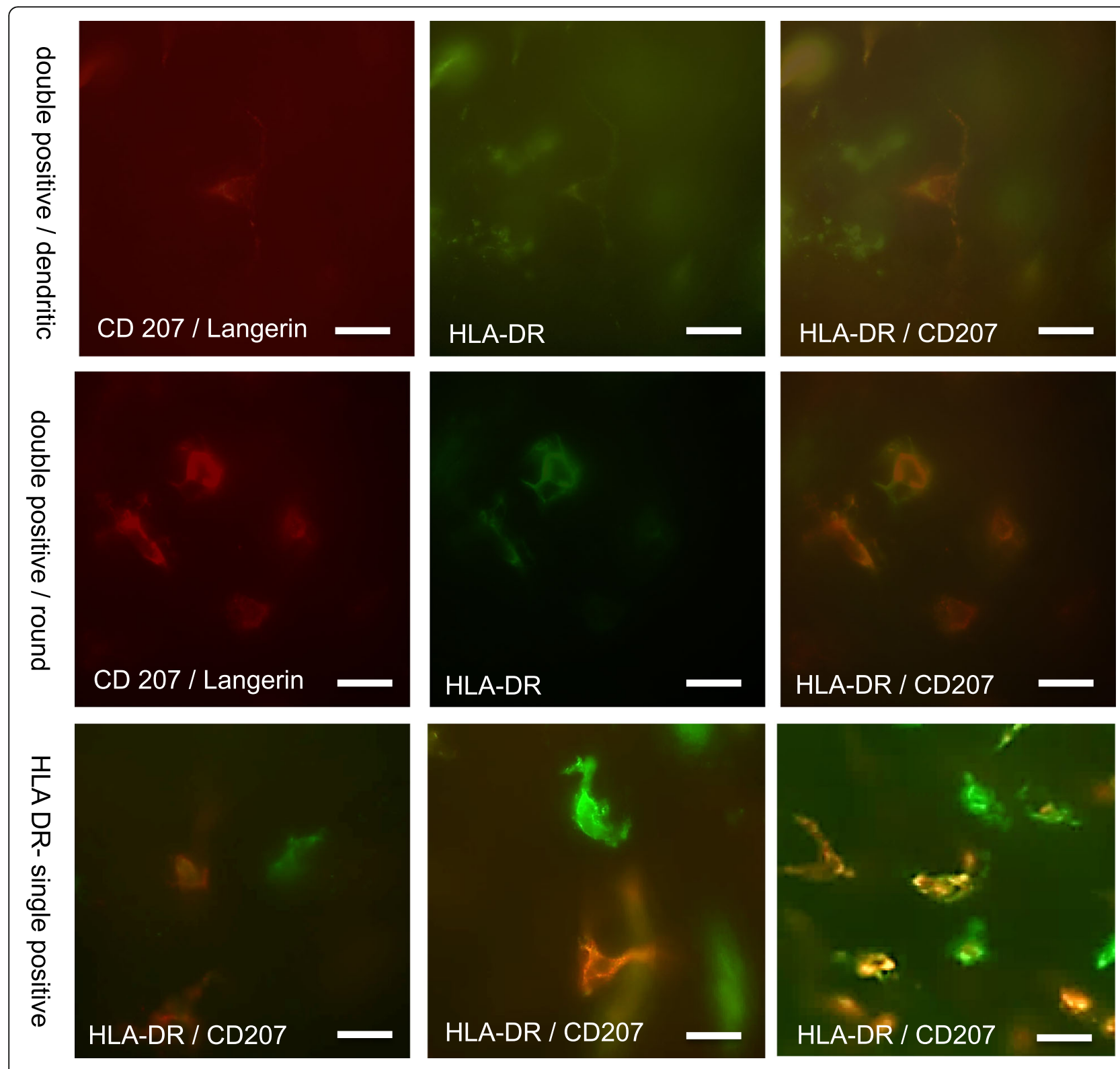

Fig. 6 Morphology of epidermal LCs (dendritic, round). Note rare examples of HLA-DR single positive epidermal cells. Scale bar represents 10 um 


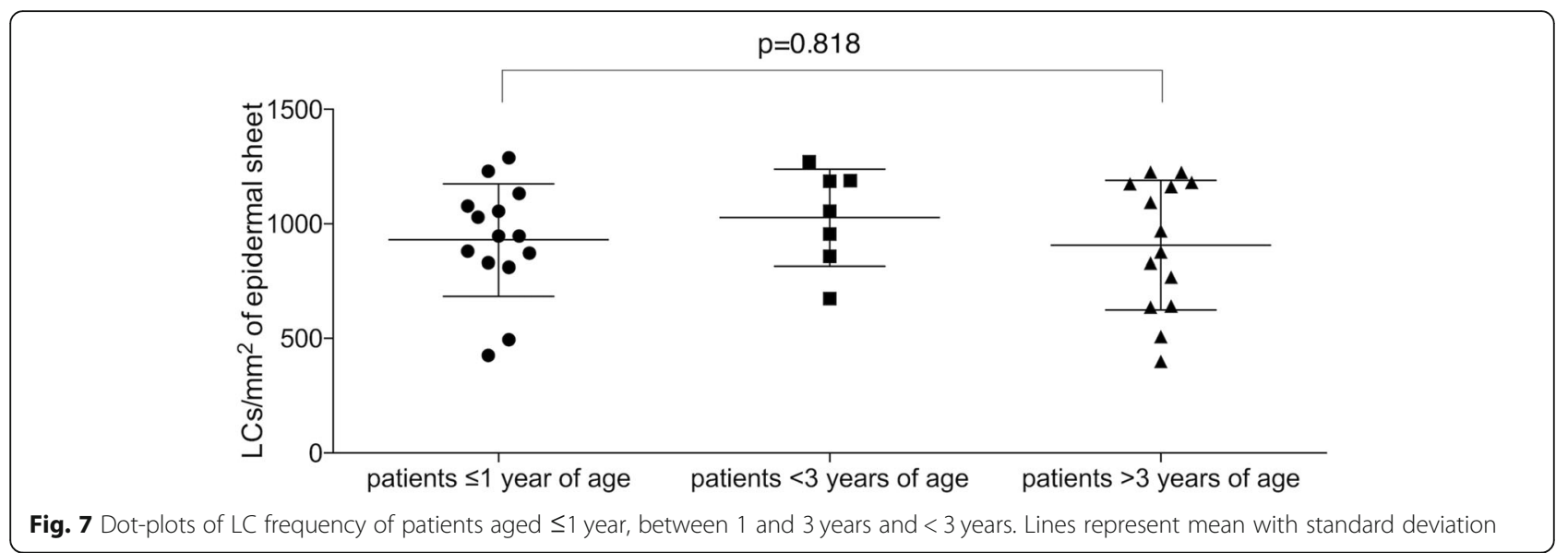

density was assessed. CD207-positive cells were considered LCs.

In the epidermis, we found a mean of $31.8 \pm 2.7 \mathrm{LCs}$ per $\mathrm{mm}^{2}(n=11)$ in samples from patients without penile malformation as compared to $30.5 \pm 1.9 \quad(n=11)$ in samples from patients with hypospadias $(p=0.697)$. In patients with distal hypospadias the LC frequency was similar as compared to those with proximal hypospadias $(28.2 \pm 2.1, n=7$ vs. $34.4 \pm 3.1, n=4, p=0.13)$.

In the dermis a mean LC frequency per $\mathrm{mm}^{2}$ of $5.9 \pm$ $0.9, \mathrm{n}=11$ was assessed in patients without penile malformations whereas the LC frequency in hypospadias patients accounted to $7.5 \pm 1.3, \mathrm{n}=11(p=0.329)$ Figs. 8 and 9 .

Morphology was comparatively analyzed on samples of about 100 LCs each in epidermis and dermis. $8.4 \%$ of all epidermal LCs were round as compared to $91.6 \%$ with a dendritic appearance. In contrast, virtually all (99.1\%) dermal CD207/Langerin + cells had a round shape. There was no difference in the proportion of shapes of LCs comparing patients with and without penile malformations.

\section{Discussion}

By thorough evaluation using two different methods our data demonstrate that LCs are present in patients with hypospadias in the same frequency and morphology as in foreskin from children without penile malformation. Consequently, we assume that their ontogeny is not disturbed and we hypothesize their immunological function is preserved in hypospadias patients.

The relevance of this finding - negative data - becomes apparent in view of the altered (fore) skin embryology and the changes to skin function in hypospadias patients as well as when considering the role of LCs in the foreskin in sexually transmitted diseases, notably HIV and HPV. Both are not only very common but also associated with a massive burden of morbidity.
Hypospadias are linked to early embryological changes at time of outgrow of the genital tubercle starting from gestational week 8 , when mesenchymal signaling, notably involving FGF, which is required for the outgrow of the genital tubercle, determines epithelial differentiation. Mesenchymal FGF signaling has been shown to affect ectodermal as well as endodermal epithelia [4]. In a murine model, ectodermal deletion of FGFR2 resulted in the most severe hypospadias with major alterations to the foreskin, highlighting a major role of FGFR2 in the developing genital surface epithelia [3]. Various changes in skin development and marker allocation have been shown to occur as a consequence [2, 12]. Foreskin derived fibroblasts from children with hypospadias react differently to endocrine stimuli, possibly based on genetic variation in these subjects [13]. Furthermore, a subcutaneous muscle layer, termed the "dartos fascia" has been shown to be disorganized in patients with hypospadias [14]. This evidence highlights the impact of early fetal events during the outgrow of the genital tubercle on the development of penile skin in boys with hypospadias.

Androgen and estrogen receptors as well as molecules responsible for their regulation, notably ZEB1, are expressed differently in skin of hypospadias patients $[5,15]$. Interestingly, ZEB1 has also been implicated in the regulation of the fate of $\mathrm{CD}^{+} \mathrm{T}$-cells [16] and has been shown to be relevant in LC maturation [17]. This points at a possible relationship between androgen receptor regulation being involved in the embryology of hypospadias and the functioning of the specific immune system - including LCs.

LCs acquire their typical immunophenotye gradually during fetal life and after birth. It has been shown in a mouse model, that Langerin is expressed only after birth [18]. Another prototypical marker of LCs, the NF-kB activator RANK, is already expressed by the end of the second trimester in adult like levels [19]. LC precursor cells, however, are present in the dermis as early as 

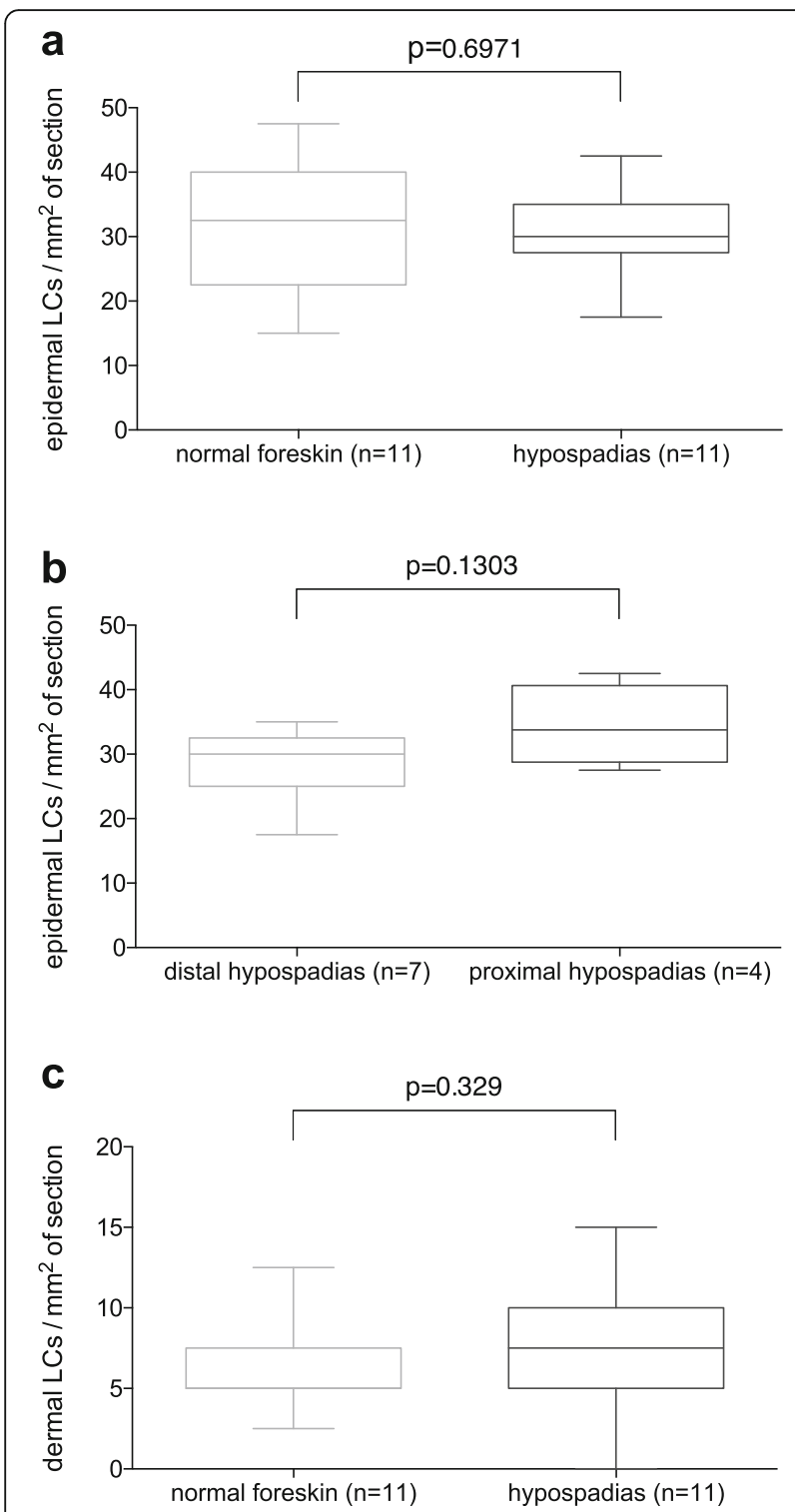

Fig. 8 Box-plots of mean Langerhans cell (LC) counts per $\mathrm{mm}^{2}$ on immunohistochemically stained full skin sections comparing a patients without penile malformations to all included patients with hypospadias, b patients with distal hypospadias to patients with proximal hypospadias, and $\mathbf{c}$ dermal LC counts per $\mathrm{mm}^{2}$ in patients without penile malformations to all included patients with hypospadias. Error bars represent min-max

gestational week 9-14 [20]. This matches the timeframe, when - at the level of the genital tubercle - changes become effective that ultimately lead to the formation of hypospadias [1]. Consequently, finding a frequency of LCs unchanged compared to patients without penile malformation, might be interpreted as evidence for an unhindered colonization of the penile skin with immune precursor cells in early fetal life. Our findings would suggest that the penile skin epithelium might be less affected by the underlying genetic changes, at least with regard to the skin-resident Langerhans cells.

LC frequency in human foreskin as well as in the glandular epithelia has been assessed multiply, notably in connection with HIV research. The LC frequency in vaginal and foreskin epithelium was found to be high, comparable to our results. Also, an age related difference in LC frequency in foreskin epidermis has been described [21]. In our study, we could not observe different LC frequency dependent on patients' age.

LCs are critically involved in HIV infection, with the removal of the foreskin leading to a reduced probability of female to male transmission from 2.49 to $1.18 \%$ [7, 22]. Independent from LC frequency also the polarity of exposition was found to modify the probability of infection with the inner foreskin being more susceptible to HIV infection [23]. Our findings might be interpreted as indirect evidence that males affected by hypospadias carry the same risk of HIV infection compared to those who have no genital malformation. However, lacking a direct proof this remains hypothetical but fits the lack of reports about excess HIV infection rates in hypospadias patients. Removal of foreskin during hypospadias surgery implies the same relative protection in hypospadias patients as compared to others.

HPV infects basal epithelial cells [24]. The presence of foreskin is related to the likelihood of transmission from men to women as well as the likelihood of persistence of infection [25]. Unlike in HIV infection, LCs play a critical role in modifying the response of the immune system to the HPV infection. The presence of $\mathrm{T}$ regulatory cells - presumably a result of lacking co-stimulation by LCs - in HPV associated cervical cancer lesions has been shown to probably be associated to worse outcomes [26]. Furthermore LCs are critically involved in rendering T-cells unresponsive and thereby allowing for HPV progression [8]. Penile cancer is relatively rare and often associated with HPV. Additionally, a role in the inhibition of cutaneous carcinogenesis has been attributed to LCs in a murine model for squamous cell cancer [27].

Like for HIV, our finding of an unchanged frequency of LCs in hypospadias patients points at a risk of HPV infection similar to that of a non-hypospadias population, however, without direct proof.

Preoperative hormonal treatment is commonly used, mainly for proximal hypospadias to increase glandular diameter and penile girth in order to prevent postoperative complications. It has been shown in an animal model, that androgen stimulation induces topical inflammation, what could be relevant to LC activation and migration [28]. The lag time between androgen application and surgery in our patients was at least 4 weeks whereas there was no "testosterone holiday" in the abovementioned animal model. Furthermore, we used topical 

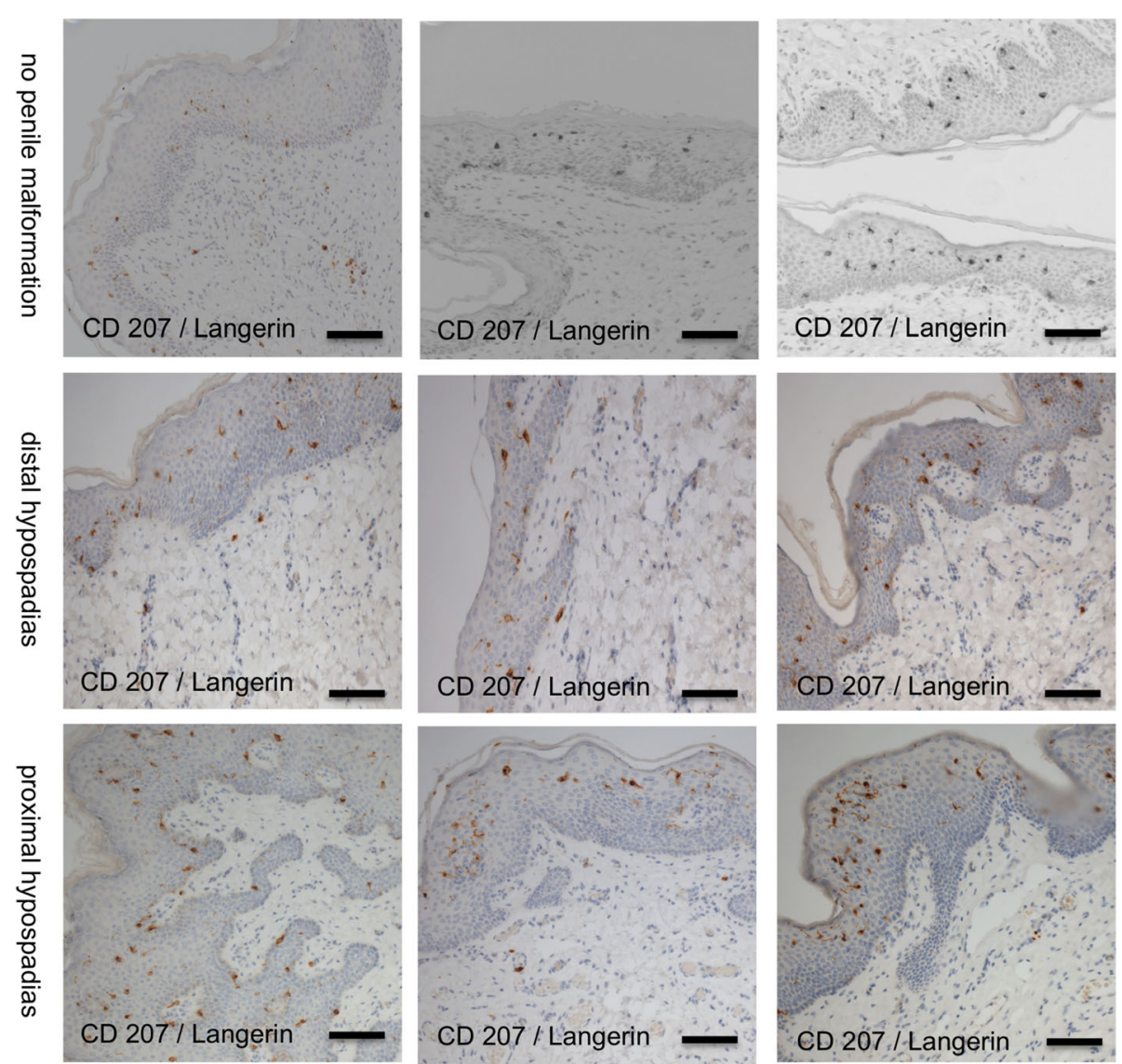

Fig. 9 Immunohistochemically stained full skin sections with anti-Langerin (929F3.01). Scale bar represents 100 um

dihydrotestosterone whereas in the cited study, intramuscular testosterone was applied. In our patient cohort, 5/7 proximal hypospadias received a preoperative topical treatment with dihydrotestosterone ointment. As there was no difference in LC frequency, we conclude that preoperative androgen application - with a "testosterone holiday" of 4 weeks and topical administration does not prompt LC migration by a topical inflammatory response.

Studying potential repercussions of embryological events in human tissues implicates a number of limitations. Prenatal sampling of skin is unprecedented in humans; such research would require an animal model, as to our ends also for genital malformations. We are limited to describing the state of LCs after birth, however, we cannot draw any conclusions on whether the ontogeny and the colonization of skin by these cells during embryological developments is as normal as their appearance in our samples. Moreover and most importantly, the lack of a functional evaluation of the LCs, e.g. by induction of inflammation prior to tissue sampling, that is not possible due to ethical concerns, limits the scope of our study. We therefore rely on the presence of physiological numbers of LCs as an indicator of their normal functioning. The dermal compartment, that is critical for LC traffic and the functioning of the immune system, could only be assessed on sections. With regard to the data on LC ontogeny and as elaborated above, however, the choice to investigate the frequency and anatomy of LCs after birth by sheet and section analysis seemed an important and logical step. In case of a disrupted embryological colonization, changes were to be expected [18].

In view of these limitations, the conclusions made herein are limited to a snap-reading of physiological LC frequency. With these findings relying on a meticulous sampling excluding any bias and two different methods for analysis (sheets and sections), however, the data itself seem undisputable. Furthermore this is the first report in literature to assess LCs in children with penile malformations.

For future research, refined techniques such as multicolour-flow-cytometry of skin cell suspensions or single-cell-transcriptome-analyses may reveal peculiarities of the immune system in the skin of hypospadias patients $[29,30]$. Furthermore, animal models with inducted penile malformations, as for example FGF10 of 
FGFR2 knockout mice could help shedding more light onto LC ontogeny, postnatal animal models could address the question of LC functionality [31, 32].

\section{Conclusions}

Langerhans cells are present in the foreskin of hypospadias patients in a normal frequency and morphology compared to patients without penile malformation. This might suggest that patients with hypospadias are not different from patients with normal penile development considering their specific skin immunity, at least considering the epidermal compartment. Functional aspects as well as the dendritic cell subset composition of the dermis remain to be studied.

\section{Abbreviations \\ A488: Alexa Fluorochrome 488 (green); A594: Alexa Fluorochrome 594 (red); BSA: bovine serum albumine; CD: cluster of differentiation; DAPI: 4',6- Diamidin-2-phenylindol (blue); HIV: Human Immunodeficiency Virus; HLA: Human Leucocyte Antigen; HPV: Human Papilloma Virus; ICH: Immunohistochemistry; LC: Langerhans Cell; PBS: phosphate buffered saline}

\section{Acknowledgements}

The authors would like to thank the staff of the Laboratory for Langerhans Cell Research at the Department for Dermatology and Venereology and at the histopathological laboratory at the Section for Clinical and functional Anatomy, both at the Medical University Innsbruck, Austria for their patient support. Furthermore we would like to thank Dr. Becker, Dr. Koen and Dr. Berger for their help with patient recruitment and sample acquisition during hypospadias surgery at the Department for Pediatric Urology, Ordensklinikum Linz, Hospital of the Sisters of Charity.

Part of this data have been presented at the Annual Conference of the European Association of Urology (EAU) 2018 and therefore the abstract is published in European Urology Supplements. The Abstract published does not exceed the word limit of 400:

Haid B, Reider D, Spinoit AF, Nägele F, Pechriggl E, Romani N, Oswald J. Is the skin immune system compromised in patients with hypospadias? Eur Urol Suppl 2018;17:e995.

\section{Authors' contributions}

$\mathrm{BH}, \mathrm{NR}$ and JO drafted the study protocol, NR, HF and JO supervised the manuscript drafting and the whole experimental work. $\mathrm{BH}$ wrote the manuscript. $\mathrm{BH}$ presented the project to the ethics committee, $\mathrm{BH}$ and AFS retrieved all samples and prepared epidermal and dermal sheets. DR performed the laboratory analysis of all sheets including immunofluorescent staining and cell counting. FN and EP performed the sections staining and preparation, $\mathrm{FN}$ and $\mathrm{BH}$ did the cell counting on sections. All authors read, edited and approved the manuscript including all figures.

\section{Funding}

This project was partly funded by the Tyrolean Science Fund (TWF-2014-128). The funds provided were used to finance laboratory expenses (antibodies, reagents). The funding bodies played no role in the design of the study and collection, analysis, and interpretation of data and in writing the manuscript

\section{Availability of data and materials}

The datasets generated and/or analysed during the current study are available over Zenodo, https://zenodo.org/record/1323160\#.XL4Vey9XbUI

\section{Ethics approval and consent to participate}

This study has been approved by the ethics committee of the Hospital of the Sisters of Charity, Linz, Austria (EK22/14). All parents of the included children signed a consent form for the anonymized processing of the skin samples taken intraoperatively.
Consent for publication

Not applicable.

\section{Competing interests}

The authors declare that they have no competing interests.

\section{Author details}

${ }^{1}$ Department of Pediatric Urology, Hospital of the Sisters of Charity, Ordensklinikum Linz, Seilerstätte 4, 4020 Linz, Austria. ${ }^{2}$ Department of Urology, Ludwig Maximilians University, Marchioninistraße 15, 81367 Munich, Germany. ${ }^{3}$ Department for Dermatology and Venereology, Medical University Innsbruck, Anichstraße 35, 6020 Innsbruck, Austria. ${ }^{4}$ Section for clinical and functional Anatomy, Medical University Innsbruck, Müllerstraße 59, 6020 Innsbruck, Austria. ${ }^{5}$ Department of Urology, University Clinic Gent, Corneel Heymanslaan 10, 9000 Gent, Belgium. ${ }^{6}$ Department of Plastic, Reconstructive and Aesthetic Surgery, Medical University Innsbruck, Innerkoflerstraße 1, Innsbruck, Austria.

Received: 22 April 2019 Accepted: 31 October 2019

Published online: 12 November 2019

\section{References}

1. Bouty A, Ayers $K L$, Pask A, Heloury $Y$, Sinclair AH. The genetic and environmental factors underlying hypospadias. Sex Dev. 2015;9:239-59.

2. Kurzrock EA, Baskin LS, Li Y, Cunha GR. Epithelial-mesenchymal interactions in development of the mouse fetal genital tubercle. Cells Tissues Organs. 1999:164:125-30.

3. Gredler ML, Seifert AW, Cohn MJ. Tissue-specific roles of fgfr 2 in development of the external genitalia. Development. 2015;142:2203-12.

4. Harada M, Omori A, Nakahara C, Nakagata N, Akita K, Yamada G. Tissuespecific roles of FGF signaling in external genitalia development. Dev Dyn. 2015;244:759-73.

5. Qiao L, Tasian GE, Zhang H, Cao M, Ferretti M, Cunha GR, et al. Androgen receptor is overexpressed in boys with severe hypospadias, and ZEB1 regulates androgen receptor expression in human foreskin cells. Pediatr Res. 2012;71:393-8.

6. Steinman RM. Dendritic cells: understanding immunogenicity. Eur J Immunol. 2007;37(Suppl 1):S53-60.

7. Ganor Y, Bomsel M. HIV-1 transmission in the male genital tract. Am J Reprod Immunol. 2011;65:284-91.

8. Woodham AW, Yan L, Skeate JG, van der Veen D, Brand HE, Wong MK, et al $T$ cell ignorance is bliss: T cells are not tolerized by langerhans cells presenting human papillomavirus antigens in the absence of costimulation. Papillomavirus Res. 2016;2:21-30.

9. Valladeau J, Ravel O, Dezutter-Dambuyant C, Moore K, Kleijmeer M, Liu Y, et al. Langerin, a novel c-type lectin specific to langerhans cells, is an endocytic receptor that induces the formation of birbeck granules. Immunity. 2000;12:71-81.

10. Schuster C, Vaculik C, Fiala C, Meindl S, Brandt O, Imhof M, et al. HLA-DR+ leukocytes acquire CD1 antigens in embryonic and fetal human skin and contain functional antigen-presenting cells. J Exp Med. 2009;206:169-81.

11. Ober-Blöbaum JL, Ortner D, Haid B, Brand A, Tripp C, et al. Monitoring skin dendritic cells in steady state and inflammation by immunofluorescence microscopy and flow cytometry. In: Inflammation methods and protocols. New York: Springer Science and Business Media; 2017. p. 37-53.

12. Pechriggl EJ, Bitsche $M$, Blumer MJF, Fritsch $H$. The male urethra: spatiotemporal distribution of molecular markers during early development. Ann Anat. 2013;195:260-71.

13. Qin X-Y, Sone H, Kojima Y, Mizuno K, Ueoka K, Muroya K, et al. Individual variation of the genetic response to bisphenol a in human foreskin fibroblast cells derived from cryptorchidism and hypospadias patients. PLoS One. 2012;7:e52756.

14. Spinoit A-F, Van Praet C, Groen L-A, Van Laecke E, Praet M, Hoebeke P. Congenital penile pathology is associated with abnormal development of the dartos muscle: a prospective study in a large cohort of children undergoing primary penile surgery at a tertiary referral center. J Urol. 2014.

15. Qiao L, Tasian GE, Zhang H, Cunha GR, Baskin L. ZEB1 is estrogen responsive in vitro in human foreskin cells and is over expressed in penile skin in patients with severe hypospadias. J Urol. 2011;185:1888-93. 
16. Guan T, Dominguez CX, Amezquita RA, Laidlaw BJ, Cheng J, Henao-Mejia J, et al. ZEB1, ZEB2, and the mir-200 family form a counterregulatory network to regulate CD8+T cell fates. J Exp Med. 2018.

17. Konradi S, Yasmin N, Haslwanter D, Weber M, Gesslbauer B, Sixt M, et al. Langerhans cell maturation is accompanied by induction of $\mathrm{n}$-cadherin and the transcriptional regulators of epithelial-mesenchymal transition ZEB1/2. Eur J Immunol. 2014;44:553-60.

18. Tripp $\mathrm{CH}$, Chang-Rodriguez S, Stoitzner P, Holzmann S, Stössel H, Douillard $P$, et al. Ontogeny of langerin/CD207 expression in the epidermis of mice. J Invest Dermatol. 2004;122:670-2.

19. Schöppl A, Botta A, Prior M, Akgün J, Schuster C, Elbe-Bürger A. Langerhans cell precursors acquire RANK/CD265 in prenatal human skin. Acta Histochem. 2015;117:425-30.

20. Schuster C, Mildner M, Mairhofer M, Bauer W, Fiala C, Prior M, et al. Human embryonic epidermis contains a diverse langerhans cell precursor pool. Development. 2014;141:807-15.

21. Hussain LA, Lehner T. Comparative investigation of langerhans' cells and potential receptors for HIV in oral, genitourinary and rectal epithelia. Immunology. 1995;85:475-84.

22. Tobian AAR, Serwadda D, Quinn TC, Kigozi G, Gravitt PE, Laeyendecker O, et al. Male circumcision for the prevention of HSV-2 and HPV infections and syphilis. N Engl J Med. 2009;360:1298-309.

23. Ganor Y, Zhou Z, Tudor D, Schmitt A, Vacher-Lavenu M-C, Gibault L, et al. Within 1 h, HIV-1 uses viral synapses to enter efficiently the inner, but not outer, foreskin mucosa and engages langerhans-t cell conjugates. Mucosal Immunol. 2010:3:506-22.

24. Raff AB, Woodham AW, Raff LM, Skeate JG, Yan L, Da Silva DM, et al. The evolving field of human papillomavirus receptor research: a review of binding and entry. J Virol. 2013;87:6062-72.

25. Grabowski MK, Kong X, Gray RH, Serwadda D, Kigozi G, Gravitt PE, et al. Partner human papillomavirus viral load and incident human papillomavirus detection in heterosexual couples. J Infect Dis. 2016;213:948-56.

26. van Esch EMG, van Poelgeest MIE, Trimbos JBMZ, Fleuren GJ, Jordanova ES, van der Burg SH. Intraepithelial macrophage infiltration is related to a high number of regulatory $\mathrm{T}$ cells and promotes a progressive course of hpvinduced vulvar neoplasia. Int J Cancer. 2015;136:E85-94.

27. Ortner D, Tripp CH, Komenda K, Dubrac S, Zelger B, Hermann M, et al. Langerhans cells and NK cells cooperate in the inhibition of chemical skin carcinogenesis. Oncoimmunology. 2017;6:e1260215.

28. Hofer MD, Cheng EY, Bury MI, Xu W, Hong SJ, Kaplan WE, et al. Androgen supplementation in rats increases the inflammatory response and prolongs urethral healing. Urology. 2015;85:691-7.

29. Alcántara-Hernández $M$, Leylek $R$, Wagar LE, Engleman EG, Keler T, Marinkovich MP, et al. High-Dimensional phenotypic mapping of human dendritic cells reveals interindividual variation and tissue specialization. Immunity. 2017;47:1037-1050.e6.

30. Villani A-C, Satija R, Reynolds G, Sarkizova S, Shekhar K, Fletcher J, et al. Single-cell rna-seq reveals new types of human blood dendritic cells, monocytes, and progenitors. Science 2017;356: 6335, eaah4573.

31. Petiot A, Petiot A, Perriton CL, Dickson C, Cohn MJ. Development of the mammalian urethra is controlled by Fgfr2-IIlb. Development. 2005;132:2441-50.

32. Ober-Blöbaum JL, Ortner D, Haid B, Brand A, Tripp C, Clausen BE, et al. Monitoring skin dendritic cells in steady state and inflammation by immunofluorescence microscopy and flow Cytometry. Methods Mol. Biol. New York, NY: Springer New York; 2017;1559:37-52.

\section{Publisher's Note}

Springer Nature remains neutral with regard to jurisdictional claims in published maps and institutional affiliations.

Ready to submit your research? Choose BMC and benefit from:

- fast, convenient online submission

- thorough peer review by experienced researchers in your field

- rapid publication on acceptance

- support for research data, including large and complex data types

- gold Open Access which fosters wider collaboration and increased citations

- maximum visibility for your research: over $100 \mathrm{M}$ website views per year

At BMC, research is always in progress.

Learn more biomedcentral.com/submissions 